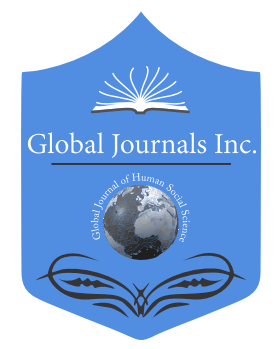

\title{
Tertiary Education Technology Management towards Studying Willingness Approaches: A Sociological Perspective
}

By Joel Laffita Rivera

European College for Liberal Studies (ECLS)

Abstract- Without the shadow of a doubt, the use of technology has become not only an inseparable part of our daily lives but, it is also changing with not coming back the way we look at future societies living styles. So much so the truth that we already ponder is matter of a forthcoming civilized world living concept. And unless a catastrophic would happen, this is the scenario we do portray. With this, the study aimed to analyze tertiary education technology management towards studying willingness approaches. It also provides based research study blended learning methodological insights. To accomplish this objective, a revision of reliable materials such as academic scripts, books, and Internet accredited websites was conducted. This research criterium involved the mixed of quantitative and qualitative research techniques. The present research study takes up on technology individuals rate usage which affective-paraphernalia has led to the high degree of self-reliance and self-direct individuals' behaviors we all can observe in these days university students. All this to create a body of knowledge about this particular phenomenon.

Keywords: sociology; education; behaviorism; technology; blended learning.

GJHSS-G Classification: FOR Code: 130399

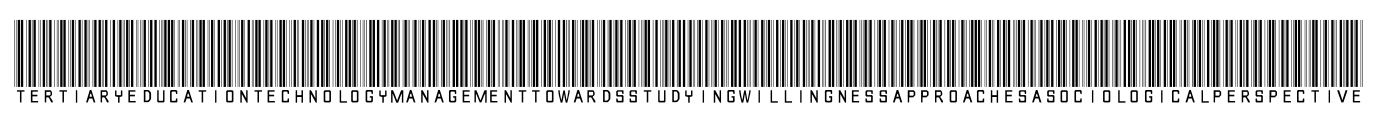

Strictly as per the compliance and regulations of:

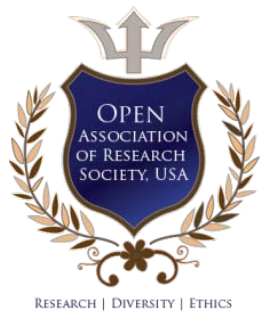

(C) 2021. Joel Laffita Rivera. This is a research/review paper, distributed under the terms of the Creative Commons AttributionNoncommercial 3.0 Unported License http://creativecommons.org/licenses/by-nc/3.0/), permitting all non-commercial use, distribution, and reproduction in any medium, provided the original work is properly cited. 


\title{
Tertiary Education Technology Management towards Studying Willingness Approaches: A Sociological Perspective
}

\author{
Joel Laffita Rivera
}

\begin{abstract}
Without the shadow of a doubt, the use of technology has become not only an inseparable part of our daily lives but, it is also changing with not coming back the way we look at future societies living styles. So much so the truth that we already ponder is matter of a forthcoming civilized world living concept. And unless a catastrophic would happen, this is the scenario we do portray. With this, the study aimed to analyze tertiary education technology management towards studying willingness approaches. It also provides based research study blended learning methodological insights. To accomplish this objective, a revision of reliable materials such as academic scripts, books, and Internet accredited websites was conducted. This research criterium involved the mixed of quantitative and qualitative research techniques. The present research study takes up on technology individuals rate usage which affectiveparaphernalia has led to the high degree of self-reliance and self-direct individuals' behaviors we all can observe in these days university students. All this to create a body of knowledge about this particular phenomenon.
\end{abstract}

Keywords: sociology; education; behaviorism; technology; blended learning.

\section{InTRODUCTION}

W ithout the shadow of a doubt, the use of technology has become not only an inseparable part of our daily lives but, it is also changing with not coming back the way we look at future societies living styles. So much so the truth that we already ponder is matter of a forthcoming civilized world living concept. And unless a catastrophic would happen, this is the scenario we do portray. Of course, university students are included. This particular segment of modern society [well-known as Millenniums] has become so habitual to technology usage that living without it is not an option to be considered, at least is what most of them bearing in mind. This is a posture that is understood as resulting from being born and grow up in an era ruled by a spectrum of technological advancements for instance, computers, tablets, smartphones and, more significantly, Internet and Digital Platforms. So. for these days' university students is not a bit issue to cope with these technologies. However, the frequent use they give them has created a strong-whole in terms of affective-paraphernalia leading to a high

Author: European College for Liberal Studies (ECLS), Branch Campus Madrid, Spain.e-mail: joel.globaljournals@gmail.com degree of self-reliance and self-direct individuals' behaviors. A phenomenon that the present research study attempts to analyze from the sociological perspective proposed: Tertiary Education Technology Management towards Studying Willingness Approaches.

Pragmatically speaking we, all know that today the technology background of university students is much advanced than it was years ago. As the digitalization process develops, so does their knowledge respectively. (Stephen, 2020) claims that the pace of technological advancement shows no signs of slowing, and we certainly won't be returning to simpler times barring catastrophic turns of events, so that so alarm that going digital could be the only way to keep up with the rapid pace of the modern world. Consequently, it should be the based subject's knowledge university students are imparted, and which they can acquire wherever they are, wherever go. At the time they want to do so when using technology. It would be a matter of studying willingness approaches.

All this raises these fundamental questions: Are university students willing to perform research given assignments according to Higher Education learning standards by using technology? If so, why universities still struggle to cope with studying willingness approaches? What if the solution rests on critically analyzing these days university students' behaviors in technology management?

Taking on those questionable statements, it would be very accurate to say that is not a secret that the younger generations, including these days university students occupy the highest presence percentage when it comes to technology usage. It is not either a hidden thing that the time they do spend in doing digital platforms online communication practices is higher than the one other segments of modern societies do. We can certainly argue that $80 \%$ to $90 \%$ of the knowledge and skills they do posse when it comes to digital platforms usage is acquired through self-learning-engagements. So, these are clear indicators of behavioral selfautonomous learning approaches. In other words, a matter of willingness which the university should use to cultivate such research capabilities towards the production of university students skilled-graduates. 
(Araiba, 2019) argues that although behaviorists generally accept the important role of heredity in determining behavior, they focus primarily on environmental events. Subsequently, it is implicit that the technology self-reliance and self-direct individuals' behaviors the present research study highlights is a point of departure to access studying willingness approaches through the creation of blended learning inductive behavioral methodologies in Tertiary Education.

\section{il. Literature Review}

Although the conceptual discussion on the subject this research study presents might well appear subjectively, yet it is important to realize that sociology as a social science discipline uses various methods of empirical investigations and critical analysis to develop a body of knowledge about social order and social change (Ashley and David, 2005).

The philosophical view used to address the aim of this paper matches reliable and competent theories such as; The theory of Digital Sociology which tries to understand the use of digital media as part of everyday life and how these various technologies contribute to patterns of human behavior and social relationships. The New Theory of Education which valuable principles can help universities to understand that the insights provided in this study are beneficial to the learning process in Tertiary Educational. Both the theory of Digital Sociology and New Theory of Education have been addressed and discussed in the research-work of (Lawrence, 1978); (Selfe, 1987); (Wynn, 2009); (Neal, 2010); (Devorah, 2014); (Richard, 2006); (Ashley, 2005).

The sociological perspective presents in this paper copes with the concept of sociology recorded in (The American Heritage Science Dictionary, 2011), which states that Sociology is the study of society, human social behavior, patterns of social relationships, social interaction, and culture that surrounds everyday life. It also copes with other scientific, academic research accounts that have stepped into the field of technology usage to address its implication in Higher Education. A study conducted at the University of Florida to analyze university student's technology ownerships, showed that 95 percent of undergraduate students own a laptop or a smartphone and 30 percent own a laptop, a smartphone, and a tablet (Christopher, 2017). These statistics results should not surprise us because they are clear indicators of technological advancements exposures, something that these students have been experiencing throughout the course of their lives.

The (National Center for Education Statistics, 2018) which is the primary federal entity for collecting, analyzing, and reporting data related to education in the United States and other nations, published a paper which highlights the growth and use of computers and the Internet among children and juveniles. Using computers and the Internet is more widespread among children and adolescents ages 5 through 17 than among adults. Although the publication was limited to analyze USA society, we all know that the constant evolution of these technologies has not stopped. For the contrary, due to the incursion and development of the Digital Age, it continues expanding and gaining amply terrene in all sectors of modern societies, including Higher Education. (Darejan, 2015) cites that the reality today proves the fact that information technologies are more and more often used in the higher education system. An example to be cited is the use of the Blended Learning method. (Skrypnyk, 2015) cites that Blended Learning is a Tech-Instructive Approach whose main objective is to use the technological advances of the Digital Era to benefit the Education sector in general. This method describes the way e-learning is combined with traditional classroom methods to create a hybrid teaching methodology. Although the methodological implications of this method have had their criticism, many research studies show a very positive view of its valuable academic results. (Westberry, 2009) quotes that blended learning enhances higher cognitive skills, promotes reflection, and gives equal opportunities to learners. (Lopez, 2011) claims that the method is capable of improving learning outcomes, and (Laffita, 2020) affirms that the blended learning method helps change behavioral studies approaches. As (Beetham, 2013) quotes, it is time for rethinking the way we manage technology in Education.

\section{BlENDED LEARNing IndUCtive Behavioral Approach}

Based on evidence-based-technology-impact in education, we have to say that there was never before other time in human history in which the university, as an integral part of a society, was gifted to access and utilize the huge among of knowledge databases and computer tools applications that at present, technology has put at its disposal through Internet, Google search appliances, Digital Libraries, Websites, and an assortment of Digital Platforms. These tech mediums have provided the pathway for the university to create a blended learning curriculum based on blended learning inductive behavioral methods. In other words, taking advantage of the high degree of self-reliance and self-direct individuals' behaviors university students do show when using all kinds of electronic devices, Internet service providers, and digital platforms to access in that direction studying willingness approaches. See diagram 1: Blended Learning Inductive Behavioral Approach created for this educational purpose. Table 1: Blended Learning Behavioral Approach Evaluation Criteria, and table 2: Pilot Blended Learning Classroom Setting: 


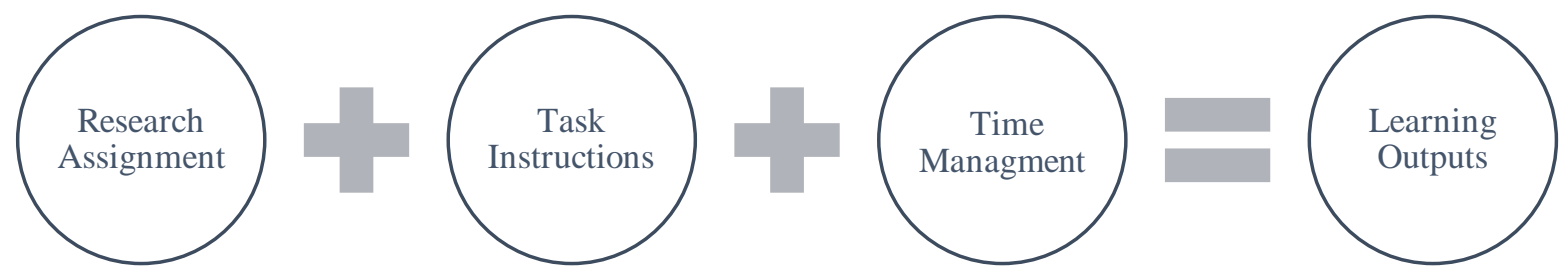

Diagram 1: Blended Learning Inductive Behavioral Approach

Table 1: Blended Learning Behavioral Approach Evaluation Criteria

\begin{tabular}{c|cc}
\hline Subject & Rewarded Marks & Method Implications \\
\hline Subjective Assignments & Pass and Fail & Research Assign \\
& & Task Instruction \\
Objective Assignments & & Time Management \\
& & Learning Outputs \\
\hline
\end{tabular}

Table 2: Pilot Blended Learning Classroom Setting

\begin{tabular}{|c|c|c|c|}
\hline Based Subject Matter & Instruction & $\begin{array}{l}\text { Time Managment } \\
\text { Diggesting Learning } \\
\text { Inputs }\end{array}$ & Study Show Case \\
\hline $\begin{array}{l}\text { SPANISH FOR CULTURE } \\
\text { AND COMMUNICATION }\end{array}$ & $\begin{array}{l}\text { Provide clear instructions } \\
\text { on what to do. }\end{array}$ & $\begin{array}{l}\text { Allocate sufficient time } \\
\text { according to given } \\
\text { curriculum loading hrs. }\end{array}$ & $\begin{array}{l}\text { Online Individual/group } \\
\text { Presentations }\end{array}$ \\
\hline 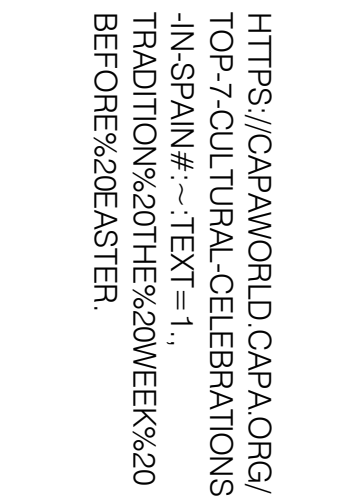 & $\begin{array}{l}\text { You are required to } \\
\text { search the following topic: } \\
\text { Spanish belief } \\
\text { celebrations. Prepare a } \\
\text { written and spoken report } \\
\text { in which you discuss } \\
\text { cultures using appropriate } \\
\text { terminology for cultural } \\
\text { characteristics, and } \\
\text { recognize the impact of } \\
\text { these cultures in today } \\
\text { Spanish society social- } \\
\text { relationships }\end{array}$ & - & $\begin{array}{c}\text { Google Forms } \\
\text { Google Classroom } \\
\text { Google Meet } \\
\text { Microsoft Teams }\end{array}$ \\
\hline
\end{tabular}

Scientifically, it is proved that learners learn more when they are actively involved in the learning process. So, we should teach assignments this way. The brainstorming of the implications shown in the diagram and the tables consists in utilizing the potential of the technological, environmental stimuli surrounding these days university students to develop that way research cognitive individuals' capabilities among undergraduate and postgraduate students. The blended learning inductive behavioral method would permit students not to work under pressure. At the same time, they will not be able to justify unfinished online research assignments. So, allocating sufficient time management is crucial for learners to digest learning inputs. It will allow teachers to determine behavioral studying willingness approaches by using computer tool applications as mediators.

\section{Methodology}

To make up the literature framework of the research study, which is based on 1) Research methodology. 2) Subject matter domain. 3) Results and discussion; we utilized mixed quantitative and qualitative research techniques. We focused on collecting, analysing, and mixing both quantitative and qualitative data because both research methods work together offer the best way to address the subject-matter presented. This criterium encompassed the revision of reliable materials such as academic scripts, books, and Internet accredited websites. The inputs of this search are displaced throughout the literature framework of the manuscript according to research writing principles. Three fundamental questions were accountable to proceed with the present investigation, which attempts to respond them have been contextualized and 
sustained by accomplishing the study objective, which analyses tertiary education technology management towards studying willingness approaches, and provides based research study blended learning methodological insights.

\section{Fundamental Questions}

Are university students willing to perform research given assignments according to Higher Education learning standards by using technology? If so, why universities still struggle to cope with studying willingness approaches? What if the solution rests on critically analyzing these days university students' behaviors in technology management?

\section{Result and Discussion}

The research study has featured comprehended facets of the subject matter exposed to discuss technology dependency issues that characterize behavioral management approaches. The implication of this philosophical idea rests primarily on the subjective and conditioned technology usage university students displaces when managing all kinds of electronic devices, Internet service providers and, more significantly, digital platforms. A tech preferential usage we all are currently witnessing among university students, and which they have learned to manage very well on their own. As mentioned before, this particular segment of modern society [well-known as Millenniums] has become so habitual to technology usage that living without it is not an option to be considered, at least is what most of them bearing in mind. However, the frequent use of those technologies has created a strong-whole in terms of affective-paraphernalia leading to a high degree of self-reliance and self-direct individuals' behaviors. Thus, the research study relates to this phenomenon to analyze Tertiary Education Technology Management towards Studying Willingness Approaches.

Given the fact that today the technology background of university students is much advanced than it was years ago. That as the digitalization process develops, so does their knowledge, respectively. That the time they do spend in doing digital platforms online communication practices is much higher than the one other segments of modern societies do. That $80 \%$ to $90 \%$ of the knowledge and skills they do posse when it comes to digital platforms usage is acquired through self-learning-engagements; we assume that a realistic and critical analysis about these observations would lead us to change the way we impart the based subject's knowledge in Tertiary Education classroom practices when using technology.

At present, university students can manage and perform learning activities wherever they are, wherever go. At the time they want to do so when using technology. It would be a matter of studying willingness approaches. Thus, we should ask ourselves what excuse someone who is a university student might have for no doing the research online given assignments as instructed and on time.

Academically, university students are expected to behave differently than they did in prior educational levels when entering the university and during their academic studies, cope with the high degree of intellectual demands, and meet the assignments criteria evaluation for undergraduate and postgraduate levels. Accordingly, universities demand that the learning management is set by education standards. Basically, these academic inputs constitute a guideline for pursuing university studies. Nevertheless, universities still struggle to cope with studying willingness approaches. Therefore, there are reasons to believe that using methodologies such as the [Blended Learning Inductive Behavioral Approach] proposed could make a difference in accessing these behavioral patterns. It is implicit that Behaviorism, also known as behavioral psychology, is a theory of learning based on the idea that all behaviors are acquired through conditioning, and conditioning occurs through interaction with the environment. Behaviorists believe that our responses to environmental stimuli shape our actions. Consequently, the frequent use of technology, which has created a strong-whole in terms of affective-paraphernalia leading to the high degree of self-reliance and self-direct individuals' behaviors. This referential matter might lead universities to consider rethinking the way we manage technology in Tertiary Education. It promises to advance understanding of educational processes related to classroom practices and the curriculum settings.

\section{Vil. Conclusion}

In conclusion, one could say that the present research study contains significant findings corresponding to the main objective of the research study. The database presented in the manuscript contextualizes the subject-matter-domain exposed. In conjunction with which the study has made available credential researchers view on the subject discussed and added new scientific ideas. At the same time, it provides an implicit methodological approach that complements the concept of Methodology, which is the contextual framework' for research, a coherent and logical scheme based on views, beliefs, and values, that guides the choices researchers make. In other words, a reflex of the philosophical, sociological perspective this study describes. Thus, this research is a valuable contribution to the field of Education, and as such, it lets at the disposition of the readers and the specialized critics for its evaluation. 


\section{RECOMMENDATION}

Based on this research study findings, it is recommended to deep analyzing [technology behavioral management patterns inference] to evaluate the setting of viable technology methodological practices into the university classroom practices and educational curriculums. By taking into account the relationship of academic skills to the real world, it is necessary to do so as the pace of technological advancement shows no signs of slowing, and going digital could be the only way to keep up with the rapid pace of the modern world. A report from (The World Bank, 2019) cites that the future of work and the increasing role of technology in value chains make tertiary education even more relevant for workers to compete in the labor market forces. So, the way we use technology will have a positive or negative impact on future university graduates' lives productivity. Thus, it would be intelligent to consider doing future research works based on the sociological perspective this research study has presented. Overall, to look at the educative side of using technology in corresponding with Higher Education principles.

\section{ACKNOWLEDGEMENT}

The author is very thankful to all the associated personnel in any reference that contributed to this study. The research holds no conflict of interest. It is not funded through any local or foreign monetary source other than being sponsored by the professional interest of its author.

\section{BIOGRAPHY}

1. Ashley, D. (2005) Sociological Theory: Classical Statements (6th ed.). Boston: Pearson Education.

2. Araiba, S. (2019). "Current diversification of behaviorism". Perspectives on Behavior Science. 43 (1):157-175. doi:10.1007/s40614-019-00207-0. PMC 7198672. PMID 32440649.

3. Beetham, H., \& Sharpe, R. (Eds.). (2013). Rethinking pedagogy for a digital age: Designing for 21st century learning. routledge.

4. Christopher Brooks Jeff Pomerants ECAR (2017) Study of Undergraduate Students and Information Technology.

5. Devorah, L. (2014). Digital Sociology. Library of Congress Cataloging-in-Publication Data ISBN: 9781-138-02276-8 (hbk)

6. Darejan, G. (2015) Using the Internet and Computer Technologies in Learning/Teaching Process ISSN 2222-1735.

7. Lopez-Perez, M. V., Perez-Lopez, M. C., \& Rodriguez-Ariza, L. (2011). Blended learning in higher education: Students' perceptions and their relation to outcomes. Computers and Education, 56(3), 818-826.
8. Lawrence, J. (1978). The 'New' Sociology of Education and the Study of Learning Environments: Prospects and Problems https://doi.org/10.1177/ 000169937802100104

9. Laffita, J. (2020) A Study on Computer Teaching and Learning Language Assisted: Impacting Educational Behaviorisms 13th International Conference of Education, Research and Innovation ISBN978-84-09-24232-0

10. Philip W. Jackson (1978) THE NEW SOCIOLOGY OF EDUCATION, The Review of Education, 4:1, 1-5, DOI: $10.1080 / 0098559780040103$

11. Neal, R. (2010) Expanding Sentience: Introducing Digital Sociology for moving beyond Buzz Metrics in a World of Growing Online Socialization. Lulu

12. National Center for Education Statistics. (2018). Student Access to Digital Learning Resources Outside of the Classroom (NCES 2017-098), Executive Summary.

13. Richard, J. (2006) New Developments in the New Sociology of Education. https://doi.org/10.1080/ 0142569800010105

14. Stephen, W. (2020) Digital Platforms: A Brief Introduction.

15. Skrypnyk, O., Joks, S., Kovanovic, V., Dawson, S., Gasevic, D., \& Siemens, G. (2015). The History and State of Blended Learning. Alberta, Canada: Athabasca University.

16. Selfe P.L. (1987) Theories and Methods in Sociology. In: Advanced Sociology. Palgrave, London. https://doi.org/10.1007/978-1-349-1309311

17. The American Heritage Science Dictionary. 2011. "sociology." Dictionary.com. Random House. Retrieved 20 April 2020.

18. Wynn, J. (2009) Digital sociology: emergent technologies in the field and the classroom. Sociological Forum, 24(2), 448-456

19. Westberry, N. (2009). An Activity Theory Analysis of Social Epistemologies in Tertiary-level eLearning Environments (UnPublished Doctoral dissertation). University of Waikato, Hamilton, New Zealand.

20. World Bank. Retrieved 9 December 2017 "Tertiary Education".

\section{Internet Acreditated Websites}

https://revisesociology.com/2017/04/04/sociologicalperspectives-key-concepts/

https://study.com/academy/lesson/sociologys-fourtheoretical-perspectives-structural-functional-socialconflict-feminism-symbolic-interactionism.html

https://open.lib.umn.edu/sociology/chapter/16-2sociological-perspectives-on-education/

https://en.wikipedia.org/wiki/Digital sociology\#: :text= Digital\%20sociology\%20is\%20a\%20-sub,and\%20concep ts\%20of\%20the\%20self. 
https://www.verywellmind.com/behavioral-psychology4157183

https://journals.sagepub.com/doi/10.1177/00016993780

2100104

https://www.mindflash.com/elearning/what-is-blended-

learning 